\title{
Study on Corrosion Inhibition Performance of 1,2-Dithiolane-3- pentanoicacid on X65 Steel in 0.5 M Sulfuric Acid
}

\author{
Shiying Tao ${ }^{1,2, *}$, Hui Huang ${ }^{3, *}$ \\ ${ }^{1}$ Faculty of Science and Engineering, The University of Nottingham Ningbo China, Ningbo 315100, \\ P R China \\ ${ }^{2}$ Ningbo Nottingham New Materials Institute Ltd., Ningbo 315040, P R China \\ ${ }^{3}$ School of Materials and Chemical Engineering, Ningbo University of Technology, Ningbo 315211, P \\ R China \\ *E-mail: sytao_nbu@163.com, Carey.Tao@nottingham.edu.cn, huihuang@nbut.edu.cn
}

doi: $10.20964 / 2019.06 .68$

Received: 12 February 2019 / Accepted: 7 April 2019 / Published: 10 May 2019

\begin{abstract}
1,2-Dithiolane-3-pentanoicacid(DLP) has been tested for corrosion inhibition properties of X65 steel using a variety of experimental methods at $298 \mathrm{~K}$ in $0.5 \mathrm{M} \mathrm{H}_{2} \mathrm{SO}_{4}$. Electrochemical methods include classical polarization curves and electrochemical impedance spectroscopy. Electrochemical tests show that DLP can effectively inhibit the corrosion of X65 steel, and it is a mixed-type corrosion inhibitor. Morphological tests include atomic force microscopy and scanning electron microscopy. The morphology test results are highly consistent with the electrochemical experiments. In addition, quantum chemical calculations and molecular dynamics simulations were used to calculate DLP. Both experimental and theoretical results show that DLP exhibits excellent corrosion inhibition performance for X65 steel. The adsorption of DLP on the surface of X65 steel is consistent with Langmuir adsorption. And adsorbed on the surface of X65 by physicochemical adsorption.
\end{abstract}

Keywords: Corrosion inhibitor, X65 steel, Electrochemical method, Atomic force microscope, Scanning electron microscope, Theoretical calculation

\section{$\underline{\text { FULL TEXT }}$}

(C) 2019 The Authors. Published by ESG (www.electrochemsci.org). This article is an open access article distributed under the terms and conditions of the Creative Commons Attribution license (http://creativecommons.org/licenses/by/4.0/). 